\title{
Common Fundamentals of Psoriasis and Depression
}

\author{
Stefanie HÖLSKEN ${ }^{1 \#}$, Frederik KREFTING2\#, Manfred SCHEDLOWSKI ${ }^{1,3}$ and Wiebke SONDERMANN ${ }^{2}$ \\ ${ }^{1}$ Institute of Medical Psychology and Behavioral Immunobiology, '2Department of Dermatology, Venereology and Allergology, University \\ Hospital Essen, University Duisburg-Essen, Essen, Germany and 'Department of Clinical Neuroscience, Osher Center for Integrative Medicine, \\ Karolinska Institutet, Stockholm, Sweden \\ \#Both authors contributed equally.
}

\begin{abstract}
Psoriasis is an inflammatory, immune-mediated disease that is frequently associated with psychological comorbidities such as depression. The stigma patients feel because of the appearance of their skin may contribute to the high psycho-social burden of psoriasis. However, there is emerging evidence that overlapping biological mechanisms are, to a substantial degree, responsible for the close interaction between psoriasis and depression. Increased proinflammatory mediators, such as C-reactive protein or interleukin-6, are present in both psoriasis and depression, indicating that inflammation may represent a pathophysiological link between the diseases. Anti-inflammatory biologic therapies treat the clinical manifestations of psoriasis, but might also play a significant role in reducing associated depressive symptoms in patients with psoriasis. Comparison between single studies focusing on the change in depressive symptoms in psoriasis is limited by inconsistency in the depression screening tools applied.
\end{abstract}

Key words: psoriasis; depression; psychological comorbidity; inflammation; pathophysiological link; depression screening tools.

Accepted Nov 22, 2021; Epub ahead of print Nov 22, 2021

Acta Derm Venereol 2021; 101: adv00609.

Corr: Wiebke Sondermann, Department of Dermatology, Venereology and Allergology, University Hospital Essen, University Duisburg-Essen, Hufelandstr. 55, DE-45122 Essen, Germany. E-mail: wiebke.sondermann@uk-essen.de

$\mathrm{P}$ soriasis is a chronic inflammatory disease that leads to typical erythematous, scaly skin plaques. It affects nearly 2 million people in Germany (1) and is highly associated with psychological comorbidities, such as depression and anxiety disorders $(2,3)$. Screenings of patients with psoriasis seeking help in dermatological clinics found prevalence rates for clinical depression of approximately $12-13 \%$ using International Classification of Diseases (ICD) codes (4-6). However, depending on the screening methodology, depressive symptoms are described as present in up to $28-55 \%$ of patients with psoriasis $(6,7)$. Anxiety disorders are prevalent in $7-48 \%$ of patients with psoriasis $(5,8)$. Given these high numbers of psychological comorbidities, the integrative management of patients with psoriasis in dermatological practice is essential (9-12). To this end, the establishment of an easy-to-use screening tool would be an important

\section{SIGNIFICANCE}

This review elucidates the inflammatory overlap between psoriasis and depression and provides an overview of clinical psoriasis studies that have assessed depression as an outcome measure. The implications for dermatological practice are summarized. Future studies will need to reach a consensus on specific screening tools to ensure comparability across studies and in clinical practice. The establishment of a comprehensive screening for psychological comorbidity is necessary in dermatological practice.

addition to routine clinical practice, ensuring the detection of affected patients, as these conditions are a major source of disability and may also hamper successful dermatological treatment $(13,14)$. Thus, the subject of the different screening tools will be discussed throughout this paper.

One possible explanation for the close association between psychological burden and psoriasis is the common stigmatizing attitude of society due to easily visible skin manifestations in affected patients. This hypothesis is supported by the fact that social stigmatization seems to be a strong predictor of depressive symptoms in patients with psoriasis (15). However, this relatively straightforward explanation may not be sufficient to account for all the observed effects.

Another hypothesis that is currently increasingly discussed suggests that immunological factors could be responsible for the association between depressive symptoms and inflammatory skin diseases, such as psoriasis. For years, depression has been attributed to reductions in monoaminergic neurotransmitters in the central nervous system (CNS), as monoamine agonists improve symptoms in a group of involved patients $(16-18)$. However, it is now established that cytokinemediated communication between the immune system and the brain plays a central role in the pathogenesis of depression (19-22). Studies have found increased serum levels of proinflammatory cytokines, such as tumour necrosis factor alpha (TNF- $\alpha$ ), interleukins (IL)-1, IL-1 $\beta$, IL-2, IL-6, IL-8, IL-17, IL-23, and C-reactive protein (CRP) in patients who had depression without other inflammatory comorbidities (23-27) (Fig. 1). Conversely, there is a high prevalence of depressive symptoms in patients with chronic inflammatory diseases, such as rheumatoid arthritis or inflammatory bowel disease 


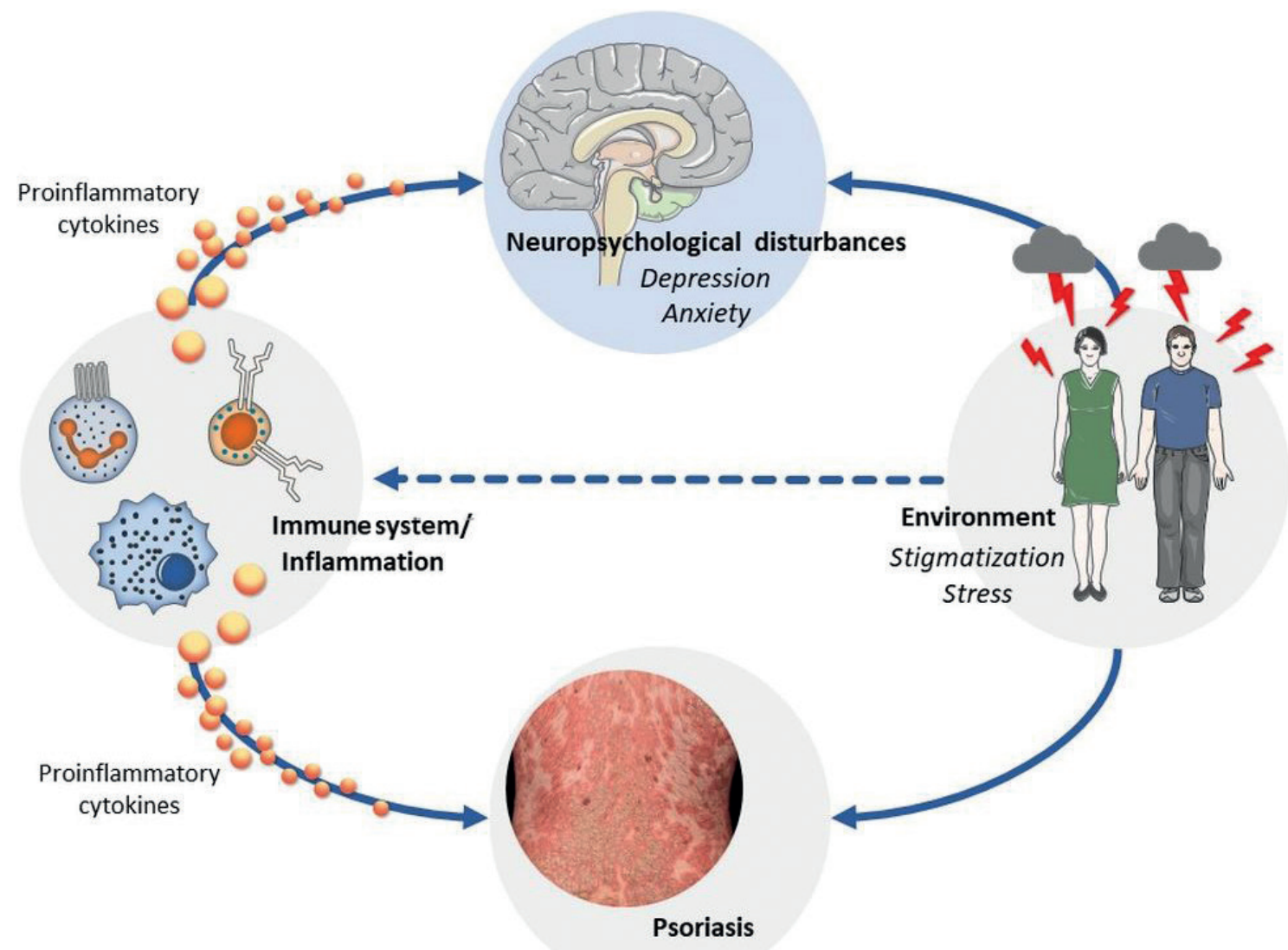

Fig. 1. Psoriasis is a chronic inflammatory disease, frequently associated with depressive symptoms, which, on the one hand, are in part induced by the appearance of the skin and the resulting stigmatization felt by patients. However, on the other hand, there is emerging evidence that increased peripheral inflammatory responses are responsible for the induction and maintenance of depressive symptoms. In addition, psycho-social stress also affects immune responses. Future research is needed to unravel these functional interconnections among inflammatory responses, psoriasis and depressive symptoms. The insights obtained need to be considered in clinical practice.

(28-30). In addition, patients on cytokine therapy treated with, for example, interferons report a high incidence of depression as unwanted side-effect $(19,20,31)$. These clinical observations are supported by experimental data in healthy subjects who develop depressive symptoms following peripheral immune challenges induced by vaccination or bacterial endotoxin injection (32-35).

There are several theories about how elevated proinflammatory cytokines might influence the metabolism of neurotransmitters within the CNS. One theory assumes a hyperpermeable blood-brain barrier in patients with major depression that allows serum proinflammatory cytokines to enter the CNS (36). Once proinflammatory cytokines are present in the CNS, they are able to activate neuronal and non-neuronal cells, similar to their mode of action in the peripheral immune system (37). Another pathway discussed in the literature is the activation of cerebral vasculature endothelial cells leading to the secretion of cytokines inside the blood-brain barrier (27, 38). A third explanatory approach assumes that peripheral inflammatory signals can be transmitted to the CNS via the vagus nerve, as vagus nerve fibres have receptors that can bind serum proinflammatory cytokines (39).
As a consequence of this theoretical approach, peripheral low-grade inflammation is increasingly seen as a potential therapeutic target in depression. Different studies investigating the anti-depressive efficacy of anti-inflammatory treatments, such as non-steroidal anti-inflammatory drugs (NSAIDs) or cytokine blockers, have been performed, in some cases with promising results $(20,22,40)$. Further studies assessing, amongst others, the anti-depressive effects of IL- 6 inhibitors, are currently recruiting specifically depressed patients with elevated levels of CRP (41). An overview of antiinflammatory agents and an assessment of their potential regarding anti-depressant treatment is available (42).

Mirroring the broadened concept of depression, psoriasis is no longer considered an isolated skin disease. Current understanding views psoriasis as a systemic inflammatory condition with documented proinflammatory reactions that go beyond the skin (43). The observation of peripheral inflammation both in psoriasis and in depression suggests that this may be one of the shared mechanisms of both diseases, underlying the high rates of psychological comorbidity and, especially, depression (for a review see, for example, 44 and 45). 


\section{THE ROLE OF INFLAMIMATION}

In light of the theories detailed above, it is relevant to take a closer look at the cytokines that play a role in both pathologies. The question, as to which serum proinflammatory cytokines show altered levels in patients with psoriasis, has been addressed in several reviews; see, for example (46-48). Dowlatshahi et al. (46) critically considered the inconsistency of methods resulting in a high heterogeneity of results. Nonetheless, the authors found sufficient evidence to state that levels of the proinflammatory cytokines IL- 6 and TNF- $\alpha$ are consistently elevated in psoriasis, in addition to CRP, E-selectin and intercellular adhesion molecule 1 (ICAM-1). These findings are supported by a more recent meta-analysis by Bai et al. (47). However, they examined a slightly different array of inflammatory markers and did not assess CRP and ICAM-1. Given the importance of IL-17 in the pathogenesis of psoriasis (49-51), an increased concentration of serum IL-17 may be expected. However, the data remains inconclusive, with some original studies showing elevated IL-17 levels (49), but both negative $(46,47)$, and positive $(48)$ results in meta-analyses.

A quite comprehensive original study analysed 157 blood proteins in 266 patients with psoriasis (52). This study found significant correlations of pre-treatment PASI with IL-17C, IL-17A, and IL-6. Thus, there is some overlap with those cytokines elevated in depression (for a review see (45)). However, with only modest differences compared with healthy controls, these immune markers do not qualify as markers of disease severity in patients with psoriasis (46).

Following the concept of a shared inflammatory burden as the reason for an overlap in symptoms, it appears likely that there might be a correlation of depressive symptoms with systemic inflammation markers in patients with psoriasis. At least on the clinical level, depression is more common in patients with severe psoriasis, underlining the cytokine hypothesis. However, patients with mild psoriasis can also have relevant mental health problems $(44,45,53)$. To the best of our knowledge, there is only one study to date that has investigated the correlation of depression in patients with psoriasis with serum inflammation markers: Pietrzak et al. (54) found serum concentrations of IL-18 to correlate with the severity of depressive symptoms in men with psoriasis $(r=0.27)$. However, care is needed in interpreting correlations, and there may be additional variables influencing both psoriasis and depression. A possible candidate would be obesity, as this is a risk factor for incident psoriasis, aggravates existing psoriasis $(55,56)$, and is itself associated with systemic inflammation (57), as well as depression (58). In their model, Pietrzak et al. (54) did not control for body mass index (BMI) and, even though they did not find a significant correlation of BMI with depression in their sample, another study found BMI to at least to be associated with health-related quality of life (HR-QoL) in patients with psoriasis (10). Future studies looking into the inflammatory overlap of psoriasis and depression should thus control for obesity.

To follow up on the inflammation approach, it may be worthwhile studying psoriatic arthritis (PsA). While this subpopulation of patients with psoriasis may, in some cases, show milder skin symptoms (59), patients with PsA are characterized by additional physical disability and, on average, exhibit higher rates of comorbid depression $(44,45,60)$. There is evidence of an increased inflammatory burden in patients with PsA compared with those with psoriasis without comorbid PsA, which is clinically also reflected in an increased cardiovascular comorbidity (61). This fits with the view that peripheral inflammatory processes represent a main linking mechanism between psoriasis and depression. More research on those 2 subpopulations of patients with psoriasis is needed in order to follow up on this idea.

The argument that the overlap of psoriasis and depression is associated with the systemic inflammation underlying both conditions would imply that, as psychological and psoriatic symptoms improve under therapy, so does the inflammatory burden. No study has addressed this directly so far. However, some studies have investigated the development of inflammatory markers under antipsoriatic therapy. One marker that has been assessed repeatedly and was found to decrease in its levels over the course of treatment is CRP (respectively high-sensitive (hs) CRP) (62-64). While data on other biomarkers is more heterogeneous, again owing to a high heterogeneity of study protocols, there is some evidence for a reduction in the levels of several proinflammatory cytokines over the course of psoriasis treatment $(52,63-65)$. Kim et al. (52) investigated blood serum of patients with moderate-to-severe psoriasis after 4 weeks of treatment with tofacitinib or etanercept and found changes in a wide range of proteins. Amongst others, IL-6 was reduced, while other markers, such as IL-17A, were reduced only in patients with marked skin improvement.

An "indirect" way to assess the influence of systemic anti-psoriatic therapies on inflammatory burden is to examine the cardiovascular risk, as it is known to be closely associated with systemic inflammation $(43,66)$. In 2015, an initial study investigated in how far TNF- $\alpha$ inhibition or therapy with methotrexate may have positive effects on cardiovascular risk in patients with rheumatoid arthritis and PsA, respectively plaque psoriasis. Limited evidence suggests that these systemic therapies are associated with a decrease in cardiovascular risk (67). Two years later, $\mathrm{Wu}$ et al. (68) expanded evidence on this issue as they demonstrated that cumulative exposure to TNF- $\alpha$ inhibitors was associated with a reduced risk of major cardiovascular events in patients with psoriasis. Later on, data from a prospective observational study showed that biologic therapy (anti-TNF- $\alpha$, anti-IL12/23, 
anti-IL17) in severe psoriasis was associated with favourable modulation of coronary plaque indices, as measured by coronary computed tomography angiography (69). A study specifically investigated the effects of the antiIL17A-antibody secukinumab on cardiovascular risk ("CARIMA" study). Limited evidence was found that secukinumab might have a beneficial effect on cardiovascular risk by improving the endothelial function of patients with plaque psoriasis (70).

While there is some evidence for the idea of psoriatic inflammation triggering depression, this association appears to be bi-directional (32). The skin manifestations of psoriasis often worsen with increasing psychological stress, and stressful life events have been shown to play a role in induction or exacerbation of psoriasis $(45,53$, 71). This clinical observation is underpinned by experimental data indicating that stress and central nervous changes can contribute to new onset or exacerbation of psoriasis via a dynamic bidirectional cross-talk between the nervous system and cutaneous immune cells. Through activation of the hypothalamic-pituitary-adrenal axis and the autonomic nervous system, chronic stress can cause a constant upregulation of the innate proinflammatory cytokine profile, including IL-1, IL-6 and TNF- $\alpha$ (72).

\section{CHANGES IN PSYCHOLOGICAL SYMPTOMS UNDER ANTI-PSORIATIC THERAPY}

Clinical psoriasis studies investigating different therapeutic agents have shown improved courses of depression under anti-inflammatory therapies (73-77). However, data in this field are relatively scarce, as only a minority of the pivotal studies to date have used psychometric scales in their assessments of quality of life in general and depressive symptoms in particular. Studies employing the Dermatological Life Quality Index (DLQI) consistently showed that systemic therapy, especially with biologic agents, in general is superior to placebo in improving skin-related quality of life (78-80). These data suggest an improvement in psychological well-being under therapy; however, HR-QoL encompasses more than just symptom reduction, mobility and time spent on treatment. This is reflected by the fact that one-third of patients who screened positive for depression or anxiety were found to have inconspicuous scores on the DLQI, which illustrates the insufficiency of the DLQI as a sole screening tool (5).

In addition to the DLQI, some of the pivotal studies included the Short Form Health Survey-36 (SF-36), a generic instrument not specifically tailored for dermatological diseases (81), including subscales analysing physical as well as mental well-being, enabling comparison between distinct diseases. The SF-36 mental scores were found to be improved after treatment with ustekinumab (PHOENIX) (82) and brodalumab compared with placebo (phase-II study) (83) and secukinumab compared with fumaric acid esters ("PRIME" trial) (84). In addition, a 1-arm study also found improvements in the short version SF-12 after treatment with adalimumab (85).

One common instrument to assess symptoms of anxiety and depression in the clinical context is the Hospital Anxiety and Depression Scale (HADS). This scale was employed, e.g. in the PHOENIX (74), AMAGINE-1 (86) and VOYAGE $(74,87)$ trials, which reported significantly improved symptoms of anxiety and depression over the course of treatment with ustekinumab, brodalumab and guselkumab, respectively, compared with the placebo groups. The HADS scores also improved in several observational studies without a placebo control group after treatment with adalimumab (85) and etanercept (14, 88-90).

Another well-known measure for the assessment of depressive symptoms is Beck's Depression Inventory (BDI). This scale was employed in 2 older studies assessing the efficacy of etanercept $(91,92)$ and reported improved BDI scores over the course of treatment. However, this TNF- $\alpha$ antagonist is hardly prescribed anymore in plaque psoriasis.

Table I presents an overview of studies on biologic anti-psoriatic treatments that included psychological measures beyond the DLQI. In addition to the measures described above, some measures were employed only in single studies $(91,93)$.

So far, no meta-analysis has focussed on the question of an improvement in depressive symptoms under anti-inflammatory treatment exclusively in patients with psoriasis. However, studies employing different approaches have reported associations between improvement in psoriasis and amelioration of psychological symptoms under biologic therapies $(74,91,93)$. In addition, anti-inflammatory treatment has demonstrated an anti-depressant effect in patients with inflammatory diseases $(76,77)$.

\section{FROM BENCH TO BEDSIDE}

Current understanding of psoriasis has evolved from a mere skin condition to a multifactorial systemic disease. In parallel, there is increasing evidence suggesting an association between depression and inflammation. Proinflammatory cytokines, such as CRP and IL-6, are elevated in both psoriasis and depression, indicating that the inflammatory process may represent a pathophysiological link between these diseases.

Fittingly, large epidemiological studies confirm that the risk of comorbid depression is significantly higher in individuals with psoriasis compared with those without $(94,95)$. In consideration of the high rate of depression and other psychological disorders, such as anxiety in patients with psoriasis, routine screening for psychological comorbidities is essential in dermatological practice to manage these patients interdisciplinarily 
Table I. Overview of psychological assessments used in studies on anti-psoriatic treatments employing tumour necrosis factor-alpha, interleukin-(12)/23 and -17 inhibitors

\begin{tabular}{|c|c|c|c|c|c|c|}
\hline Measure & Study & Medication & Design & Number of patients & Outcome & $\begin{array}{l}\text { Confirmation of } \\
\text { hypothesis?* }\end{array}$ \\
\hline \multicolumn{7}{|c|}{ Tumour necrosis factor-alpha inhibitors } \\
\hline \multirow[t]{5}{*}{ HADS } & $(85)$ & Adalimumab & One arm, observational & 143 & $\begin{array}{l}\text { HADS at week } 4 \text { and } 16 \text { and } \\
6 \text { months }\end{array}$ & Yes \\
\hline & $(86)$ & Etanercept & $\begin{array}{l}\text { Two groups (different } \\
\text { etanercept regimens), } \\
\text { open-label }\end{array}$ & $\begin{array}{l}711,2 \text { groups ( } 1: 1) \text { : continuous } \\
\text { and interrupted etanercept }\end{array}$ & HADS at week 54 & Yes \\
\hline & $(89)$ & Etanercept & $\begin{array}{l}\text { Two groups (different } \\
\text { etanercept regimens), } \\
\text { randomized, double-blind }\end{array}$ & $\begin{array}{l}752,2 \text { groups }(1: 1) \text { : etanercept } \\
\text { once or twice weekly }\end{array}$ & HADS at week 12 and 24 & Yes \\
\hline & $(14)$ & Etanercept & One arm, observational & 85 & HADS at 1,3 and 6 months & Yes \\
\hline & $(90)$ & Etanercept & One arm, observational & 133 & HADS at 1,3 and 6 months & Yes \\
\hline \multirow[t]{2}{*}{ BDI } & $(92)$ & Etanercept & $\begin{array}{l}\text { Two groups (different } \\
\text { etanercept regimens), } \\
\text { open-label }\end{array}$ & $\begin{array}{l}2,546,2 \text { groups }(1: 1) \text { : continuous } \\
\text { or interrupted etanercept }\end{array}$ & BDI at week 12 and 24 & Yes \\
\hline & $(91)$ & Etanercept & $\mathrm{RCT}$, placebo controlled & $\begin{array}{l}618,2 \text { groups ( } 1: 1) \text { : etanercept } \\
\text { or placebo }\end{array}$ & BDI at week 12 & Yes \\
\hline $\begin{array}{l}\text { Hamilton rating scale for } \\
\text { depression }\end{array}$ & $(91)$ & Etanercept & $\mathrm{RCT}$, placebo controlled & $\begin{array}{l}618,2 \text { groups ( } 1: 1) \text { : etanercept } \\
\text { or placebo }\end{array}$ & Ham-D at week 12 & Yes \\
\hline SF-36 mental subscore & (93) & Adalimumab & $\mathrm{RCT}$, placebo controlled & $\begin{array}{l}96,2 \text { groups ( } 1: 1) \text { : adalimumab } \\
\text { or placebo }\end{array}$ & SF-36 at week 12 & Not assessed \\
\hline SF-12 & $(85)$ & Adalimumab & Real-world, observational & 143 & $\begin{array}{l}\text { SF- } 12 \text { at week } 4 \text { and } 16 \text { and } \\
6 \text { months }\end{array}$ & $\begin{array}{l}\text { Yes (No for week } \\
4 \text { vs baseline) }\end{array}$ \\
\hline ZDS & $(93)$ & Adalimumab & $\mathrm{RCT}$, placebo controlled & $\begin{array}{l}96,2 \text { groups (1:1): adalimumab } \\
\text { or placebo }\end{array}$ & ZDS at week 12 & Yes \\
\hline \multicolumn{7}{|c|}{ Interleukin-(12)/23 inhibitors } \\
\hline \multirow[t]{2}{*}{ HADS } & $(73)$ & Ustekinumab & $\mathrm{RCT}$, placebo controlled & $\begin{array}{l}1,230,3 \text { groups ( } 1: 1: 1) \text { : } \\
\text { ustekinumab ( } 2 \text { dosages), placebo }\end{array}$ & HADS at week 12 & Yes \\
\hline & $(74)$ & Guselkumab & $\mathrm{RCT}$, placebo controlled & $\begin{array}{l}992,3 \text { groups }(2: 1: 1) \text { : } \\
\text { guselkumab, adalimumab or } \\
\text { placebo }\end{array}$ & $\begin{array}{l}\text { HADS at week } 16 \text { and week } \\
24\end{array}$ & Yes \\
\hline SF-36 mental subscore & $(82)$ & Ustekinumab & $\mathrm{RCT}$, placebo controlled & $\begin{array}{l}766,3 \text { groups ( } 1: 1: 1) \text { : } \\
\text { ustekinumab ( } 2 \text { dosages) or } \\
\text { placebo }\end{array}$ & SF-36 at week 12 & Yes \\
\hline \multicolumn{7}{|l|}{ Interleukin-17 inhibitors } \\
\hline HADS & $(87)$ & Brodalumab & $\mathrm{RCT}$, placebo controlled & $\begin{array}{l}\text { 633, } 3 \text { groups ( } 1: 1: 1) \text { : } \\
\text { brodalumab ( } 2 \text { dosages), placebo }\end{array}$ & HADS at week 12 & Yes \\
\hline \multirow[t]{2}{*}{ SF-36 mental subscore } & $(84)$ & Brodalumab & $\mathrm{RCT}$, placebo controlled & $\begin{array}{l}\text { 198, } 5 \text { groups ( } 1: 1: 1: 1: 1) \text { : } \\
\text { brodalumab ( } 4 \text { dosages) or } \\
\text { placebo }\end{array}$ & SF-36 at week 12 & $\begin{array}{l}\text { Yes (No for the } \\
\text { smallest dosage) }\end{array}$ \\
\hline & $(85)$ & Secukinumab & $\begin{array}{l}\text { RCT, compared with fumaric } \\
\text { acid ester }\end{array}$ & $\begin{array}{l}200,2 \text { groups }(1: 1) \text { : secukinumab } \\
\text { or fumaric acid ester }\end{array}$ & SF-36 at week 24 & Yes \\
\hline
\end{tabular}

*In placebo-controlled randomized controlled trials (RCTs): improvement in psychological symptoms under therapy > placebo; in studies without placebo control: improvement in psychological symptoms under therapy.

BDI: Beck's Depression Inventory; SF: Short Form Health Survey; HADS: Hospital Anxiety and Depression Scale; ZDS: Zung Self-Rating Depression Scale.

involving mental healthcare professionals whenever necessary (9-12). This is especially relevant, as some evidence suggests that baseline depression and persistent depression during treatment could be indicative of a less favourable treatment course $(14,90)$. Furthermore, when making a therapy decision, the dermatologist has to take into account that caution is required prior to prescribing the IL17-receptor blocker brodalumab and the smallmolecule apremilast in patients with depression and/or (history of) suicidal ideation behaviour (96). However, broad screening of patients with psoriasis for psychological disorders and mental health problems in general is not yet well established in Europe (97).

One reason impeding the screening of patients with psoriasis for comorbid psychological disorders might be that referral to mental healthcare is often difficult and associated with long waiting times; hence some dermatologists may not find out that their patients are in need of psychological care.

Another factor explaining the lack of screening in the clinical routine may be that there is no established screening tool for the assessment of psychological co- morbidity that is consistently recommended. A tool for the dermatological practice that is at least recommended by the German National Conference on Healthcare in Psoriasis is Whooley's "Two-Questions Test" (Table II) $(12,98,99)$. If patients answer "yes" to both questions, referral to the primary care physician, or preferably to a psychiatrist or psychotherapist, is indicated in order to clinically detect formal diagnostic criteria. However, to the best of our knowledge, this screening tool has not been used in any of the treatment studies.

Several studies that have assessed the efficacy of systemic treatments for psoriasis could show an improvement in psychological symptoms over the course of treatment $(76,77)$. However, the number of studies that have addressed this question is small. In part, this may be attributed to the fact that most pivotal trials testing new

\section{Table II. Whooley's "Two-Questions Test"}

1. "Have you frequently felt dejected, sad, glum or hopeless during the past month?" 2. "Have you taken significantly less pleasure and joy in things, which you otherwise enjoy doing, over the past month?"

Adopted from: $(12,98,99)$ 
compounds generally exclude patients with depression and suicidal ideation behaviour. Real-word, longitudinal observational studies investigating the improvement in psychological symptoms under anti-psoriatic treatment might be better suited to also making a statement on patients with clinically significant depression; however, the database is also meagre.

A question that is difficult to answer in the overall context is in how far improved depression is a direct effect of the anti-inflammatory treatment, or rather an indirect effect of the improved skin condition that leads to a better psychological status (45). To approach this question, it is worthwhile to examine how improvements in skin symptoms and psychological symptoms relate. As a major burden on the psyche of patients with psoriasis is the stigma and possible social isolation connected with the disease, a close association of objective and subjective symptom measures appears intuitive. However, results are highly heterogeneous, and correlations are seldom more than moderate, suggesting that much of the variance in psychological symptoms cannot be explained by the presence of, or changes in, skin symptoms alone.

There are several possible explanations for a relatively weak connection of objective and subjective measures. In contrast to intuition, it may not be as easy as to "cure the skin symptoms and the psyche will follow." It could rather be possible that the anti-psoriatic and thus anti-inflammatory medication exerts a direct effect on the psyche as it reduces inflammation associated with depression. On the other hand, it is also possible that the reasons for depressive behaviour and social isolation go beyond what can be cured by anti-psoriatic treatment: even though skin symptoms recede, it may be difficult to let go of habits that have developed during a lifetime of psoriasis burden (100). Early initiation of an effective anti-psoriatic therapy is of high importance in order to avoid cumulative life course impairment for affected children and adolescents $(53,101)$.

In conclusion, this review examined the literature on the interaction of psoriasis and depression, and the influence of anti-psoriatic treatment on depressive symptoms.

Depression is a frequent comorbidity of psoriasis. Previously, stigmatizing experiences were primarily believed to be responsible for this association. However, currently there is accumulating evidence that overlapping biological mechanisms contribute to the close connection of psoriasis and depression. Elevated levels of proinflammatory cytokines are present in psoriasis and depression, indicating that inflammation may represent a pathophysiological link between both diseases. As the 2 are closely related, it is difficult to differentiate whether improvement in depression is the result of a direct anti-inflammatory effect of the biologic, or rather an indirect effect of improved skin leading to amelioration of psychological symptoms. Several studies confirm improvements in both skin and psychological symptoms under biologic therapy; however, these improvements are often not as closely related as one would expect if the reduction in depressive symptoms was a direct effect of the improvement in skin symptoms. Data from meta-analyses demonstrated an anti-depressant effect of anti-cytokine treatments even if the somatic disease did not respond to treatment, which makes a direct effect of the biologic more likely. Furthermore, clinical trials indicated anti-depressant treatment effects of antiinflammatory agents, such as TNF- $\alpha$ antagonists in the treatment of depression, and new directions in targeting inflammatory mechanisms, e.g. with IL-6 inhibitors, are underway.

In order to optimize comparisons of changes in psychological symptoms under anti-psoriatic therapy across different treatment types and studies, a consensus needs to be reached on specific depression screening tools. Likewise, screening for comorbid depression should be standardized and implemented on a regular basis in dermatological practice in order to alleviate the associated psychological burden.

\section{ACKNOWLEDGEMENTS}

Funding source: Gefördert durch die Deutsche Forschungsgemeinschaft (DFG) - Projektnummer 422744262 - TRR 289- Funded by the Deutsche Forschungsgemeinschaft (DFG, German Research Foundation) - Project-ID 422744262 - TRR 289.

Conflict of interest disclosure. WS reports grants from medi $\mathrm{GmbH}$ Bayreuth, personal fees from Janssen, grants and personal fees from Novartis, personal fees from Lilly, personal fees from UCB, personal fees from Almirall, personal fees from LEO Pharma, personal fees from Sanofi Genzyme, outside the submitted work. The other authors have no conflicts of interest to declare.

\section{REFERENCES}

1. Schafer I, Rustenbach SJ, Radtke M, Augustin J, Glaeske G, Augustin M. Epidemiologie der Psoriasis in Deutschland - Auswertung von Sekundärdaten einer gesetzlichen Krankenversicherung. Gesundheitswesen 2011; 73: 308-313.

2. Tribo MJ, Turroja M, Castano-Vinyals G, Bulbena A, Ros E, Garcia-Martinez P, et al. Patients with moderate to severe psoriasis associate with higher risk of depression and anxiety symptoms: results of a multivariate study of 300 Spanish individuals with psoriasis. Acta Derm Venereol 2019; 99: 417-422.

3. Kurd SK, Troxel AB, Crits-Christoph P, Gelfand JM. The risk of depression, anxiety, and suicidality in patients with psoriasis: a population-based cohort study. Arch Dermatol 2010; 146: 891-895.

4. Dalgard FJ, Gieler U, Tomas-Aragones L, Lien L, Poot F, Jemec GBE, et al. The psychological burden of skin diseases: a cross-sectional multicenter study among dermatological out-patients in 13 European countries. J Invest Dermatol 2015; 135: 984-991.

5. Lamb RC, Matcham F, Turner MA, Rayner L, Simpson A, Hotopf $M$, et al. Screening for anxiety and depression in people with psoriasis: a cross-sectional study in a tertiary referral setting. Br J Dermatol 2017; 176: 1028-1034.

6. Dowlatshahi EA, Wakkee M, Arends LR, Nijsten T. The prevalence and odds of depressive symptoms and clinical depression in psoriasis patients: a systematic review and meta-analysis. J Invest Dermatol 2014; 134: 1542-1551. 
7. Korman AM, Hill D, Alikhan A, Feldman SR. Impact and management of depression in psoriasis patients. Expert Opin Pharmacother 2016; 17: 147-152.

8. Fleming P, Bai JW, Pratt M, Sibbald C, Lynde C, Gulliver WP. The prevalence of anxiety in patients with psoriasis: a systematic review of observational studies and clinical trials. J Eur Acad Dermatol Venereol 2017; 31: 798-807.

9. Burden AD, Hilton Boon M, Leman J, Wilson $H$, Richmond R, Ormerod AD, et al. Diagnosis and management of psoriasis and psoriatic arthritis in adults: summary of SIGN guidance. BMJ 2010; 341: c5623.

10. Sondermann W, Schreiber A, Korber A, Fiege O, Scherbaum $\mathrm{N}$, Benson S, et al. Psychosocial burden and body mass index are associated with dermatology-related quality of life in psoriasis patients. Eur J Dermatol 2020; 30: 140-147.

11. Sondermann W, Fiege O, Körber A, Scherbaum N. Psychological burden of psoriatic patients in a German university hospital dermatology department. J Dermatol 2020; 48: 794-806.

12. Radtke MA, Mrowietz U, Feuerhahn J, Harter M, von Kiedrowski R, Nast A, et al. Early detection of comorbidity in psoriasis: recommendations of the National Conference on Healthcare in Psoriasis. J Dtsch Dermatol Ges 2015; 13: 674-690.

13. Wu JJ, Feldman SR, Koo J, Marangell LB. Epidemiology of mental health comorbidity in psoriasis. J Dermatolog Treat 2018; 29: 487-495.

14. Jin W, Zhang S, Duan Y. Depression symptoms predict worse clinical response to etanercept treatment in psoriasis patients. Dermatology 2019; 235: 55-64.

15. Lakuta P, Marcinkiewicz K, Bergler-Czop B, BrzezinskaWcislo L. How does stigma affect people with psoriasis? Postepy Dermatol Alergol 2017; 34: 36-41.

16. Walsh BT, Seidman SN, Sysko R, Gould M. Placebo response in studies of major depression: variable, substantial, and growing. JAMA 2002; 287: 1840-1847.

17. Oeljeschläger B, Müller-Oerlinghausen B. Wege zur Optimierung der individuellen antidepressiven Therapie. Dtsch Arztebl International 2004; 101: 1337-1340.

18. Schneider F, Härter M, Schorr S. S3-Leitlinie/Nationale Versorgungs-Leitlinie Unipolare Depression Springer-Verlag; 2017.

19. Beurel E, Toups M, Nemeroff CB. The bidirectional relationship of depression and inflammation: double trouble. Neuron 2020; 107: 234-256.

20. Miller $\mathrm{AH}$, Raison $\mathrm{CL}$. The role of inflammation in depression: from evolutionary imperative to modern treatment target. Nat Rev Immunol 2016; 16: 22-34.

21. Salvador AF, de Lima KA, Kipnis J. Neuromodulation by the immune system: a focus on cytokines. Nat Rev Immunol 2021; 21: 526-541.

22. Roman M, Irwin MR. Novel neuroimmunologic therapeutics in depression: a clinical perspective on what we know so far. Brain Behav Immun 2020; 83: 7-21.

23. Howren MB, Lamkin DM, Suls J. Associations of depression with C-reactive protein, IL-1, and IL-6: a meta-analysis. Psychosom Med 2009; 71: 171-186.

24. Prather AA, Rabinovitz M, Pollock BG, Lotrich FE. Cytokineinduced depression during IFN-alpha treatment: the role of IL-6 and sleep quality. Brain Behav Immun 2009; 23: 1109-1116.

25. Lotrich FE, El-Gabalawy H, Guenther LC, Ware CF. The role of inflammation in the pathophysiology of depression: different treatments and their effects. J Rheumatol Suppl 2011; 88: 48-54.

26. Gimeno D, Kivimaki M, Brunner EJ, Elovainio M, De Vogli $R$, Steptoe $A$, et al. Associations of C-reactive protein and interleukin- 6 with cognitive symptoms of depression: 12year follow-up of the Whitehall II study. Psychol Med 2009; 39: 413-423.

27. Raison CL, Borisov AS, Majer M, Drake DF, Pagnoni G, Woolwine BJ, et al. Activation of central nervous system inflammatory pathways by interferon-alpha: relationship to monoamines and depression. Biol Psychiatry 2009; 65: 296-303.

28. Gold SM, Kohler-Forsberg O, Moss-Morris R, Mehnert A, Mi- randa JJ, Bullinger $\mathrm{M}$, et al. Comorbid depression in medical diseases. Nat Rev Dis Primers 2020; 6: 69.

29. Dickens C, Creed F. The burden of depression in patients with rheumatoid arthritis. Rheumatology (Oxford) 2001; 40: 1327-1330.

30. Moulton CD, Pavlidis P, Norton C, Norton S, Pariante C, Hayee B, et al. Depressive symptoms in inflammatory bowel disease: an extraintestinal manifestation of inflammation? Clin Exp Immunol 2019; 197: 308-318.

31. Dantzer R. Neuroimmune interactions: from the brain to the immune system and vice versa. Physiol Rev 2018; 98 : 477-504.

32. Kleyn CE, Talbot PS, Mehta NN, Sampogna F, Bundy C, Ashcroft DM, et al. Psoriasis and mental health workshop report: exploring the links between psychosocial factors, psoriasis, neuroinflammation and cardiovascular disease risk. Acta Derm Venereol 2020; 100: adv00020.

33. Benson S, Brinkhoff A, Lueg L, Roderigo T, Kribben A, Wilde $B$, et al. Effects of acute systemic inflammation on the interplay between sad mood and affective cognition. Transl Psychiatry 2017; 7: 1281.

34. Lasselin J, Schedlowski M, Karshikoff B, Engler H, Lekander M, Konsman JP. Comparison of bacterial lipopolysaccharideinduced sickness behavior in rodents and humans: Relevance for symptoms of anxiety and depression. Neurosci Biobehav Rev 2020; 115: 15-24.

35. Lasselin J, Lekander M, Benson S, Schedlowski M, Engler $\mathrm{H}$. Sick for science: experimental endotoxemia as a translational tool to develop and test new therapies for inflammation-associated depression. Mol Psychiatry 2021; 26: 3672-3683.

36. Najjar S, Pearlman DM, Devinsky O, Najjar A, Zagzag D. Neurovascular unit dysfunction with blood-brain barrier hyperpermeability contributes to major depressive disorder: a review of clinical and experimental evidence. J Neuroinflammation 2013; 10: 142.

37. Anisman H, Merali Z, Hayley S. Neurotransmitter, peptide and cytokine processes in relation to depressive disorder: comorbidity between depression and neurodegenerative disorders. Prog Neurobiol 2008; 85: 1-74.

38. Dantzer R, O'Connor JC, Freund GG, Johnson RW, Kelley $\mathrm{KW}$. From inflammation to sickness and depression: when the immune system subjugates the brain. Nat Rev Neurosci 2008; 9: 46-56.

39. Goehler LE, Gaykema RP, Hansen MK, Anderson K, Maier SF, Watkins LR. Vagal immune-to-brain communication: a visceral chemosensory pathway. Auton Neurosci 2000; 85: 49-59.

40. Raison CL, Rutherford RE, Woolwine BJ, Shuo C, Schettler P, Drake DF, et al. A randomized controlled trial of the tumor necrosis factor antagonist infliximab for treatment-resistant depression: the role of baseline inflammatory biomarkers. JAMA Psychiatry 2013; 70: 31-41.

41. Khandaker GM, Oltean BP, Kaser M, Dibben CRM, Ramana $\mathrm{R}$, Jadon $\mathrm{DR}$, et al. Protocol for the insight study: a randomised controlled trial of single-dose tocilizumab in patients with depression and low-grade inflammation. BMJ Open 2018; 8: e025333.

42. Kohler O, Krogh J, Mors O, Benros ME. Inflammation in depression and the potential for anti-inflammatory treatment. Curr Neuropharmacol 2016; 14: 732-742.

43. Boehncke WH. Systemic inflammation and cardiovascular comorbidity in psoriasis patients: causes and consequences. Front Immunol 2018; 9: 579.

44. Koo J, Marangell LB, Nakamura M, Armstrong A, Jeon C, Bhutani $T$, et al. Depression and suicidality in psoriasis: review of the literature including the cytokine theory of depression. J Eur Acad Dermatol Venereol 2017; 31: 1999-2009.

45. Patel N, Nadkarni A, Cardwell LA, Vera N, Frey C, Patel N, et al. Psoriasis, depression, and inflammatory overlap: a review. Am J Clin Dermatol 2017; 18: 613-620.

46. Dowlatshahi EA, van der Voort EA, Arends LR, Nijsten T. Markers of systemic inflammation in psoriasis: a systematic review and meta-analysis. Br J Dermatol 2013; 169: 
266-282

47. Bai F, Zheng W, Dong Y, Wang J, Garstka MA, Li R, et al. Serum levels of adipokines and cytokines in psoriasis patients: a systematic review and meta-analysis. Oncotarget 2018; 9: 1266-1278.

48. Zhou XY, Bao J, Huang B, Jin Y. Association between plasma interleukin-17 levels and risk of psoriasis: a meta-analysis. Clin Exp Dermatol 2017; 42: 161-166.

49. El-Moaty Zaher HA, El-Komy MHM, Hegazy RA, Mohamed El Khashab HA, Ahmed $\mathrm{HH}$. Assessment of interleukin-17 and vitamin D serum levels in psoriatic patients. J Am Acad Dermatol 2013; 69: 840-842.

50. Lynde CW, Poulin $Y$, Vender R, Bourcier M, Khalil S. Interleukin 17A: toward a new understanding of psoriasis pathogenesis. J Am Acad Dermatol 2014; 71: 141-150.

51. Nestle FO, Kaplan DH, Barker J. Psoriasis. N Engl J Med 2009; 361: 496-509.

52. Kim J, Tomalin L, Lee J, Fitz LJ, Berstein G, Correa-da Rosa $\mathrm{J}$, et al. Reduction of inflammatory and cardiovascular proteins in the blood of patients with psoriasis: differential responses between tofacitinib and etanercept after 4 weeks of treatment. J Invest Dermatol 2018; 138: 273-281.

53. Mattei PL, Corey KC, Kimball AB. Cumulative life course impairment: evidence for psoriasis. Curr Probl Dermatol 2013; 44: 82-90.

54. Pietrzak D, Pietrzak A, Grywalska E, Kicinski P, Rolinski J, Donica $\mathrm{H}$, et al. Serum concentrations of interleukin 18 and 25-hydroxyvitamin D3 correlate with depression severity in men with psoriasis. PLoS One 2018; 13: e0201589.

55. Murray ML, Bergstresser PR, Adams-Huet B, Cohen JB. Relationship of psoriasis severity to obesity using samegender siblings as controls for obesity. Clin Exp Dermatol 2009; 34: 140-144.

56. Jensen P, Skov L. Psoriasis and obesity. Dermatology 2016; 232: 633-639.

57. Pona A, Haidari W, Kolli SS, Feldman SR. Diet and psoriasis. Dermatol Online J 2019; 25: 13030/qt1p37435s.

58. Luppino FS, de Wit LM, Bouvy PF, Stijnen T, Cuijpers P, Penninx BW, et al. Overweight, obesity, and depression: a systematic review and meta-analysis of longitudinal studies. Arch Gen Psychiatry 2010; 67: 220-229.

59. Boehncke WH. Psoriasis and psoriatic arthritis: flip sides of the coin? Acta Derm Venereol 2016; 96: 436-441.

60. Wu CY, Chang YT, Juan CK, Shen JL, Lin YP, Shieh JJ, et al. Depression and insomnia in patients with psoriasis and psoriatic arthritis taking tumor necrosis factor antagonists. Medicine (Baltimore) 2016; 95: e3816.

61. Husted JA, Thavaneswaran A, Chandran V, Eder L, Rosen CF, Cook RJ, et al. Cardiovascular and other comorbidities in patients with psoriatic arthritis: a comparison with patients with psoriasis. Arthritis Care Res 2011; 63: 1729-1735.

62. Asahina A, Umezawa Y, Yanaba K, Nakagawa H. Serum Creactive protein levels in Japanese patients with psoriasis and psoriatic arthritis: long-term differential effects of biologics. J Dermatol 2016; 43: 779-784.

63. Boehncke S, Salgo R, Garbaraviciene J, Beschmann H, Hardt $\mathrm{K}$, Diehl S, et al. Effective continuous systemic therapy of severe plaque-type psoriasis is accompanied by amelioration of biomarkers of cardiovascular risk: results of a prospective longitudinal observational study. J Eur Acad Dermatol Venereol 2011; 25: 1187-1193.

64. Gkalpakiotis S, Arenbergerova M, Gkalpakioti P, Potockova J, Arenberger $\mathrm{P}, \mathrm{Kraml}$ P. Long-term impact of adalimumab therapy on biomarkers of systemic inflammation in psoriasis: results of a 2 year study. Dermatol Ther 2020; 33: e14110.

65. Pincelli C, Schafer PH, French LE, Augustin M, Krueger JG. Mechanisms underlying the clinical effects of apremilast for psoriasis. J Drugs Dermatol 2018; 17: 835-840.

66. Lockshin B, Balagula Y, Merola JF. Interleukin 17, inflammation, and cardiovascular risk in patients with psoriasis. J Am Acad Dermatol 2018; 79: 345-352.

67. Roubille C, Richer V, Starnino T, McCourt C, McFarlane $A$, Fleming $P$, et al. The effects of tumour necrosis factor inhibitors, methotrexate, non-steroidal anti-inflammatory drugs and corticosteroids on cardiovascular events in rheumatoid arthritis, psoriasis and psoriatic arthritis: a systematic review and meta-analysis. Ann Rheum Dis 2015; 74: 480-489.

68. Wu JJ, Guérin A, Sundaram M, Dea K, Cloutier M, Mulani P. Cardiovascular event risk assessment in psoriasis patients treated with tumor necrosis factor-a inhibitors versus methotrexate. J Am Acad Dermatol 2017; 76: 81-90.

69. Elnabawi YA, Dey AK, Goyal A, Groenendyk JW, Chung JH, Belur AD, et al. Coronary artery plaque characteristics and treatment with biologic therapy in severe psoriasis: results from a prospective observational study. Cardiovasc Res 2019; 115: 721-728.

70. von Stebut E, Reich K, Thaçi D, Koenig W, Pinter A, Körber $A$, et al. Impact of secukinumab on endothelial dysfunction and other cardiovascular disease parameters in psoriasis patients over 52 weeks. J Invest Dermatol 2019; 139: 1054-1062.

71. Malhotra SK, Mehta V. Role of stressful life events in induction or exacerbation of psoriasis and chronic urticaria. Indian J Dermatol Venereol Leprol 2008; 74: 594-599.

72. Ayasse MT, Buddenkotte J, Alam M, Steinhoff M. Role of neuroimmune circuits and pruritus in psoriasis. Exp Dermatol 2020; 29: 414-426.

73. Langley RG, Feldman SR, Han C, Schenkel B, Szapary P, Hsu $M C$, et al. Ustekinumab significantly improves symptoms of anxiety, depression, and skin-related quality of life in patients with moderate-to-severe psoriasis: Results from a randomized, double-blind, placebo-controlled phase III trial. J Am Acad Dermatol 2010; 63: 457-465.

74. Gordon KB, Armstrong AW, Han C, Foley P, Song M, Wasfi $Y$, et al. Anxiety and depression in patients with moderateto-severe psoriasis and comparison of change from baseline after treatment with guselkumab vs. adalimumab: results from the Phase 3 VOYAGE 2 study. J Eur Acad Dermatol Venereol 2018; 32: 1940-1949.

75. Papp KA, Reich K, Paul C, Blauvelt A, Baran W, Bolduc C, et al. A prospective phase III, randomized, double-blind, placebo-controlled study of brodalumab in patients with moderate-to-severe plaque psoriasis. Br J Dermatol 2016; 175: $273-286$.

76. Wittenberg GM, Stylianou A, Zhang $Y$, Sun $Y$, Gupta A, Jagannatha PS, et al. Effects of immunomodulatory drugs on depressive symptoms: a mega-analysis of randomized, placebo-controlled clinical trials in inflammatory disorders. Mol Psychiatry 2020; 25: 1275-1285.

77. Kappelmann N, Lewis G, Dantzer R, Jones PB, Khandaker GM. Antidepressant activity of anti-cytokine treatment: a systematic review and meta-analysis of clinical trials of chronic inflammatory conditions. Mol Psychiatry 2018; 23: 335-343.

78. Mrowietz U, Kragballe K, Reich K, Spuls P, Griffiths CE, Nast $A$, et al. Definition of treatment goals for moderate to severe psoriasis: a European consensus. Arch Dermatol Res 2011; 303: 1-10.

79. Norris D, Photiou L, Tacey M, Dolianitis C, Varigos G, Foley $P$, et al. Biologics and dermatology life quality index (DLQI) in the Australasian psoriasis population. J Dermatolog Treat 2017; 28: 731-736.

80. Mermin D, Boursault L, Milpied B, Taieb A, Ezzedine K Seneschal J. DLQI as a major criterion for introduction of systemic agents in patients with mild psoriasis. J Eur Acad Dermatol Venereol 2016; 30: 1961-1964.

81. Both H, Essink-Bot ML, Busschbach J, Nijsten T. Critical review of generic and dermatology-specific health-related quality of life instruments. J Invest Dermatol 2007; 127: 2726-2739.

82. Lebwohl M, Papp K, Han C, Schenkel B, Yeilding N, Wang Y, et al. Ustekinumab improves health-related quality of life in patients with moderate-to-severe psoriasis: results from the PHOENIX 1 trial. Br J Dermatol 2010; 162: 137-146.

83. Papp KA, Leonardi C, Menter A, Ortonne JP, Krueger JG, Kricorian $\mathrm{G}$, et al. Brodalumab, an anti-interleukin-17-receptor antibody for psoriasis. N Engl J Med 2012; 366: 1181-1189.

84. Sticherling M, Mrowietz U, Augustin M, Thaci D, Melzer N, Hentschke $C$, et al. Secukinumab is superior to fumaric acid 
esters in treating patients with moderate-to-severe plaque psoriasis who are naive to systemic treatments: results from the randomized controlled PRIME trial. Br J Dermatol 2017; 177: 1024-1032.

85. Leman J, Walton S, Layton AM, Ward KA, McBride S, Cliff $S$, et al. The real world impact of adalimumab on quality of life and the physical and psychological effects of moderateto-severe psoriasis: a UK prospective, multicenter, observational study. J Dermatolog Treat 2020; 31: 213-221.

86. Papp K, Reich K, Paul C, Blauvelt A, Toth D, Langley R, et al. Improvements in depression and anxiety with brodalumab therapy in AMAGINE-1, a phase 3 study for moderate to severe plaque psoriasis. J Am Acad Dermatol 2016; 74 : AB254.

87. Reich K, Armstrong AW, Foley P, Song M, Miller M, Shen YK, et al. Maintenance of response through up to 4 years of continuous guselkumab treatment of psoriasis in the VOYAGE 2 Phase 3 study. Am J Clin Dermatol 2020; 21: 881-890.

88. Dauden E, Griffiths CE, Ortonne JP, Kragballe K, Molta CT, Robertson $\mathrm{D}$, et al. Improvements in patient-reported outcomes in moderate-to-severe psoriasis patients receiving continuous or paused etanercept treatment over 54 weeks: the CRYSTEL study. J Eur Acad Dermatol Venereol 2009; 23: $1374-1382$.

89. Gniadecki R, Robertson D, Molta CT, Freundlich B, Pedersen R, Li W, et al. Self-reported health outcomes in patients with psoriasis and psoriatic arthritis randomized to two etanercept regimens. J Eur Acad Dermatol Venereol 2012; 26: 1436-1443.

90. Yang A, Xin X, Yang W, Li M, Yang W, Li L, et al. Etanercept reduces anxiety and depression in psoriasis patients, and sustained depression correlates with reduced therapeutic response to etanercept. Ann Dermatol Venereol 2019; 146: 363-371.

91. Tyring S, Gottlieb A, Papp K, Gordon K, Leonardi C, Wang $A$, et al. Etanercept and clinical outcomes, fatigue, and depression in psoriasis: double-blind placebo-controlled randomised phase III trial. Lancet 2006; 367: 29-35.

92. Gelfand JM, Kimball AB, Mostow EN, Chiou CF, Patel V,
Xia HA, et al. Patient-reported outcomes and health-care resource utilization in patients with psoriasis treated with etanercept: continuous versus interrupted treatment. Value Health 2008; 11: 400-407.

93. Menter A, Augustin M, Signorovitch J, Yu AP, Wu EQ, Gupta $S R$, et al. The effect of adalimumab on reducing depression symptoms in patients with moderate to severe psoriasis: a randomized clinical trial. J Am Acad Dermatol 2010; 62: 812-818.

94. Helmick CG, Lee-Han H, Hirsch SC, Baird TL, Bartlett CL. Prevalence of psoriasis among adults in the U.S.: 2003-2006 and 2009-2010 National Health and Nutrition Examination Surveys. Am J Prev Med 2014; 47: 37-45.

95. Cohen BE, Martires KJ, Ho RS. Psoriasis and the risk of depression in the US population: National Health and Nutrition Examination Survey 2009-2012. JAMA Dermatol 2016; 152: 73-79.

96. Lebowitz $E$, Lebwohl M. Review of suicide and depression in psoriasis and management of suicide warnings in patients treated with psoriasis drugs. SKIN 2019; 3: 72-81.

97. Dalgard FJ, Svensson $\AA$, Gieler U, Tomas-Aragones L, Lien $L$, Poot $F$, et al. Dermatologists across Europe underestimate depression and anxiety: results from 3635 dermatological consultations. Br J Dermatol 2018; 179: 464-470.

98. Whooley MA, Avins AL, Miranda J, Browner WS. Case-finding instruments for depression. Two questions are as good as many. J Gen Intern Med 1997; 12: 439-445.

99. Wohlrab J, Fiedler G, Gerdes S, Nast A, Philipp S, Radtke $M A$, et al. Recommendations for detection of individual risk for comorbidities in patients with psoriasis. Arch Dermatol Res 2013; 305: 91-98.

100. Trettin B, Feldman SR, Andersen F, Danbjorg DB, Agerskov $\mathrm{H}$. A changed life: the life experiences of patients with psoriasis receiving biological treatment. $\mathrm{Br}$ J Dermatol 2020; 183: $516-523$.

101. Kimball AB, Wu EQ, Guérin A, Yu AP, Tsaneva M, Gupta SR, et al. Risks of developing psychiatric disorders in pediatric patients with psoriasis. J Am Acad Dermatol 2012; 67: 651-657. 